\title{
Truncated Soluble Nogo Receptor Binds Nogo-66 and Blocks Inhibition of Axon Growth by Myelin
}

\author{
Alyson E. Fournier, Graham C. Gould, Betty P. Liu, Stephen M. Strittmatter \\ Department of Neurology and Section of Neurobiology, Yale University School of Medicine, New Haven, \\ Connecticut 06510
}

CNS myelin contains axon outgrowth inhibitors, such as Nogo, that restrict regenerative growth after injury. An understanding of the mechanism of Nogo signaling through its receptor ( $\mathrm{NgR})$ is critical to developing strategies for overcoming Nogomediated inhibition. Here we analyze the function of $\mathrm{NgR}$ domains in outgrowth inhibition. Analysis of alkaline phosphatase (AP)-Nogo binding in COS-7 cells reveals that the leucine-rich repeat domain is necessary and sufficient for Nogo binding and $\mathrm{NgR}$ multimerization. Viral infection of embryonic day 7 chick retinal ganglion cells with mutated $\mathrm{NgR}$ demonstrates that the
$\mathrm{NgR}$ C-terminal domain is required for inhibitory signaling but not ligand binding. The NgR glycosylphosphatidylinositol domain is not essential for inhibitory signaling but may facilitate Nogo responses. From this analysis, we have developed a soluble, truncated version of the Nogo receptor that antagonizes outgrowth inhibition on both myelin and Nogo substrates. These data suggest that $\mathrm{NgR}$ mediates a significant fraction of myelin inhibition of axon outgrowth.

Key words: Nogo; myelin; axon inhibition; Nogo receptor; CNS; leucine-rich repeat
The inability of injured CNS neurons to spontaneously regenerate is caused in part by the presence of myelin-associated inhibitory molecules at the CNS injury site. Multiple inhibitors have been identified in myelin (McKerracher et al., 1994; Mukhopadhyay et al., 1994; Niederost et al., 1999), and one of the most potent inhibitors may be Nogo (Caroni and Schwab, 1988a; Chen et al., 2000; GrandPre et al., 2000; Prinjha et al., 2000). This contention is supported by experiments showing that treatment with the inhibitor neutralization (IN-1) antibody, which recognizes Nogo-A, enhanced neurite outgrowth and functional recovery after CNS spinal cord injuries in rats (Caroni and Schwab, 1988b; Schnell and Schwab, 1990). However, IN-1 recognizes several other proteins in CNS myelin extracts; therefore, experiments with specific Nogo reagents are necessary to determine the relative contribution of Nogo to myelin-based axon inhibition.

Nogo is a member of the reticulon protein family, and its inhibitory activity has been demonstrated in multiple assays in both non-neuronal and neuronal cells (Chen et al., 2000; GrandPre et al., 2000; Prinjha et al., 2000; Fournier et al., 2001). The mechanism of action of Nogo inhibition may be complex, because two different inhibitory domains have been identified in the Nogo protein. Both the N-terminal portion of Nogo-A (Amino-Nogo; residues 1-1024) (Chen et al., 2000; Prinjha et al., 2000) and a 66 amino acid hydrophilic protein segment in the $\mathrm{C}$-terminal region of Nogo (Nogo-66) (GrandPre et al., 2000; Fournier et al., 2001) have inhibitory activity. Although both domains may have important biological activities, Nogo-66 is expressed on the surface of

\footnotetext{
Received Feb. 8, 2002; revised July 25, 2002; accepted Aug. 1, 2002.

This work was supported by grants to S.M.S. from the National Institutes of Health, the McKnight Foundation for Neuroscience, the Institute for the Study of Aging, and Biogen Inc. S.M.S. is an Investigator of the Patrick and Catherine Weldon Donaghue Medical Research Foundation. Purified NgREcto protein was a generous gift from Biogen Inc. (Cambridge, MA).

Correspondence should be addressed to Stephen M. Strittmatter, Department of Neurology, Yale University School of Medicine, P.O. Box 208018, New Haven, CT 06510. E-mail: stephen.strittmatter@yale.edu.

Copyright (C) 2002 Society for Neuroscience $0270-6474 / 02 / 228876-08 \$ 15.00 / 0$
}

oligodendrocytes (GrandPre et al., 2000) and has specific inhibitory effects on neurons in a soluble form. Because the epitope recognized by $\mathrm{IN}-1$ is not defined, the relative contribution of Amino-Nogo and Nogo-66 to myelin action on axons is poorly defined by published studies.

A receptor for Nogo-66 $(\mathrm{NgR})$ has been identified (Fournier et al., 2001). $\mathrm{NgR}$ is a 473 amino acid protein containing a signal sequence, a leucine-rich repeat (LRR)-type N-terminal domain, eight LRR domains, a cysteine-rich LRR-type C-terminal flanking domain, a unique $\mathrm{C}$-terminal region, and a glycosylphosphatidylinositol (GPI) anchorage site. The LRR domains of the $\mathrm{NgR}$ share moderate amino acid sequence similarity to many other LRR-containing proteins. Because other LRR proteins serve a wide variety of functions (Buchanan and Gay, 1996), they offer little insight into the mechanism of $\mathrm{NgR}$ signaling.

The presence of a GPI anchor in the $\mathrm{NgR}$ raises several issues with regard to $\mathrm{NgR}$ signaling mechanisms. First, the GPI-linked nature of $\mathrm{NgR}$ suggests an interaction with a transmembrane receptor subunit capable of intracellular signal transduction. Second, the GPI domain might play a critical role in lipid raft localization and signal transduction as shown for glial cell linederived neurotrophic factor (GDNF) family receptors (Tansey et al., 2000). Third, the GPI anchor may provide an NgR cleavage site for the release of soluble NgR from the cell surface. Such cleavage might render the affected cell insensitive to Nogo and/or modulate Nogo signaling on adjacent cells.

In this study, we attempt to clarify the mechanism of $\mathrm{NgR}$ action by systematically deleting $\mathrm{NgR}$ domains and testing these deletion mutants in both ligand binding and Nogo signaling assays. By studying alkaline phosphatase (AP)-Nogo binding in COS-7 cells, we have determined that all of the $\mathrm{NgR}$ LRR domains are required for Nogo binding. We have also identified a domain in the $\mathrm{C}$-terminal portion of $\mathrm{NgR}$ that is necessary but not sufficient for $\mathrm{NgR}$ signaling. The GPI linkage of $\mathrm{NgR}$ is not critical for Nogo signaling but may play a modulatory role in inhibitory signaling. This analysis has led to the identification of 

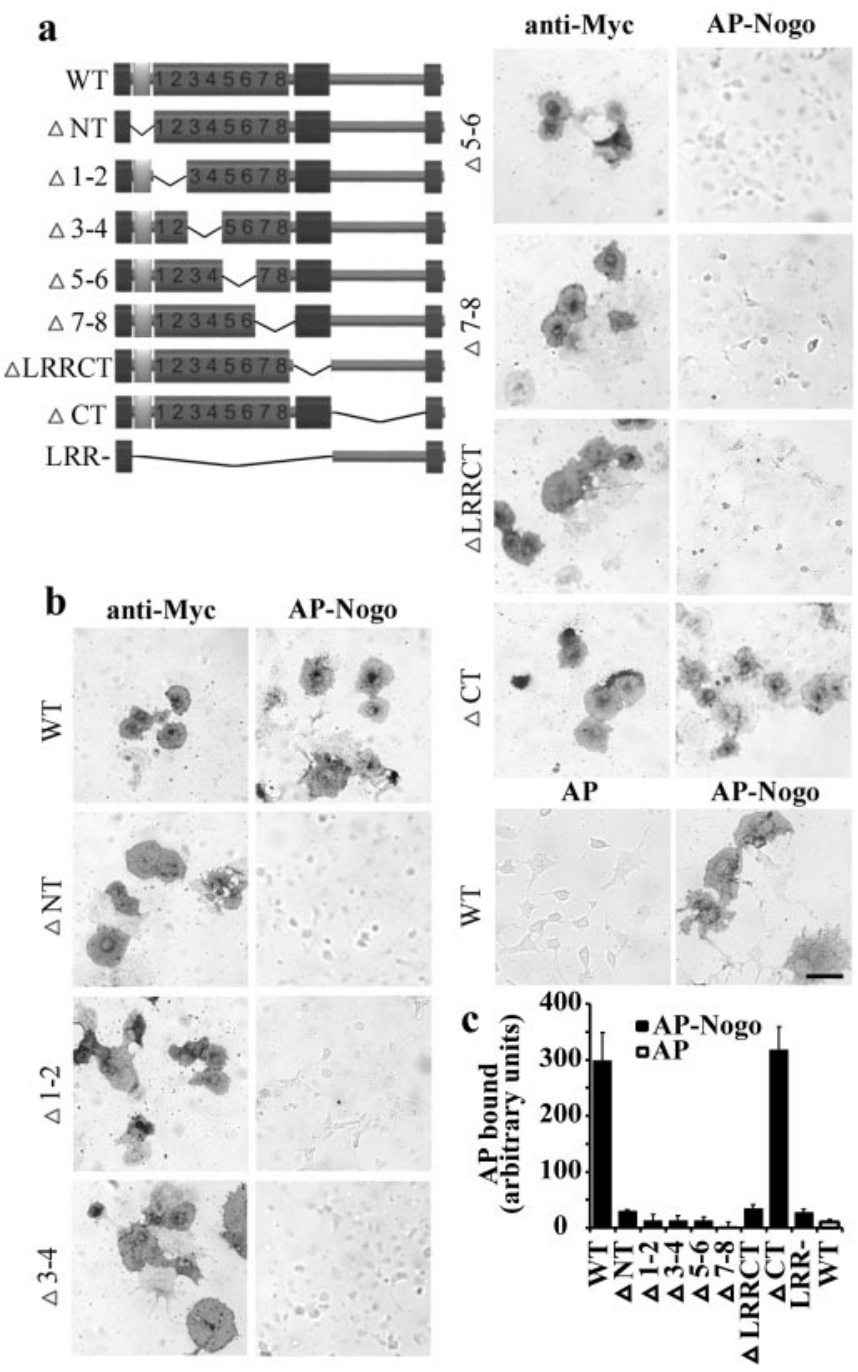

Figure 1. Nogo binding to NgR deletion mutants. $a$, Schematic of WT$\mathrm{NgR}(W T)$ and the $\mathrm{NgR}$ deletion mutants used in this study. $\mathrm{NgR}$ mutants include deletions of the N-terminus $(\Delta N T)$, LRR domains 1 and $2(\Delta 1-2)$, 3 and $4(\Delta 3-4), 5$ and $6(\Delta 5-6), 7$ and $8(\Delta 7-8)$, the LRR C-terminus $(\triangle L R R C T)$, the C-terminus $(\triangle C T)$, and the complete LRR domain $(L R R-) . b$, COS-7 cells transfected with $\mathrm{NgR}$ deletion mutant plasmids were stained for Myc immunoreactivity or tested for $20 \mathrm{~nm}$ AP or AP-Nogo binding. All NgR mutant proteins were expressed in COS-7 cells as shown by Myc immunoreactivity. Only WTNgR- and NgR $\Delta$ CTtransfected COS-7 cells bound to AP-Nogo. Scale bar, $100 \mu \mathrm{m}$. c, Quantification of AP-Nogo or AP binding to COS-7 cells transfected with $\mathrm{NgR}$ deletion mutants.

a soluble, truncated $\mathrm{NgR}$ ( $\mathrm{NgREcto})$ that antagonizes the neurite outgrowth-inhibitory effects of Nogo. NgREcto also antagonizes myelin-dependent inhibition, suggesting that signaling through the $\mathrm{NgR}$ mediates a significant proportion of myelin inhibition.

\section{MATERIALS AND METHODS}

Nogo receptor deletion mutants and chimeras. Myc-tagged mouse wildtype $\mathrm{NgR}$ (WTNgR) in pSecTag2Hygro (Invitrogen, Burlingame, CA) (Fournier et al., 2001) was used as a template for $\mathrm{NgR}$ deletion and chimeric mutants. To generate $\mathrm{NgR}$ with the $\mathrm{CT}$ region deleted $(\mathrm{NgR} \Delta \mathrm{CT}$ ), the LRR region (residues 1-310) and GPI region (residues 445-473) were amplified separately, ligated together at a NotI site, and then ligated into the Bam $\mathrm{H} 1 / X h o$ I sites of pSecTag2. LRR deletions were generated using the ExSite PCR-based site-directed mutagenesis kit (Stratagene, La Jolla, CA). Deletions were as follows: $\mathrm{NgR} \Delta \mathrm{NT}$, residues 1-57; $\mathrm{NgR} \Delta 1-2$, residues $58-105 ; \mathrm{NgR} \Delta 3-4$, residues 106-154;
NgR $\Delta 5-6$, residues 155-202; NgR $\Delta 7-8$, residues 203-250; and NgR $\Delta$ LRRCT, residues 260-310. NgRCT (residues 310-445) was amplified and cloned into the BamH1/EcoR1 site of pGEXTAG2. Cloning of HSVPlexA1 (herpes simplex virus-plexin A1) has been described previously (Takahashi et al., 1999). To construct HSVWTNgR, HSVNgRCT, and $\mathrm{HSVNgR} \Delta \mathrm{CT}$, the corresponding $\mathrm{NgR}$ was amplified with the signal sequence from pSecTag2 and ligated into the HindIII/SalI sites of pHSV PrPUC. The HSV transfer vector for the $\mathrm{NgRL} 1$ chimeric protein was constructed by substituting the cDNA encoding amino acids 1-451 of mouse $\mathrm{NgR}$ for the neuropilin-1 coding region in the HSVNP1-L1 vector (Nakamura et al., 1998).

Purified $\mathrm{NgRE}$ cto protein was a generous gift from Biogen Inc. (Cambridge, MA). To construct NgREcto, cDNA encoding amino acids 1-310 of rat $\mathrm{NgR}$ was cloned by PCR into the expression vector PV90, and the resulting plasmid was transfected into $\mathrm{CHO}$ cells. Amino acid substitutions were present, resulting in the following sequence: MKRASAGGSR LLAWVLWLQA WRVATPCPGA CVCYNEPKVT TSCPQQGLQA VPTGIPASSQ RIFLHGNRIS YVPAASFQSC RNLTILWLHS NALAGIDAAA FTGLTLLEQL DLSDNAQLRV VDPTTFRGLG HLHTLHLDRC GLQELGPGLF RGLAALQYLY LQDNNLQALP DNTFRDLGNL THLFLHGNRI PSVPEHAFRG LHSLGRLLLH QNHVARVHPH AFRDLGRLMT LYLFANNLSM LPAEVLVPLR SLQYLRLNDN PWVCGCRARP LWAWLQKFRG SSSEVPCNLP QRLAGRDLKR LAASDLQGCA. A clone derived by limiting dilution that was expressing high levels of $\mathrm{NgREcto}$ was expanded in serum-free culture medium. Conditioned medium was collected, and NgREcto was purified by cation-exchange chromatography on an SP-Sepharose column. The resultant protein was $\sim 85 \%$ pure. N-Terminal sequence analysis of the rat NgR1 (1-310) product verified that the mature protein started with Cys-27, which matched the predicted start site.

Preparation of recombinant proteins. To construct the AP-NgR vector, the $\mathrm{NgR}$ coding sequence from residues $27-451$ was ligated in frame with the signal sequence-histidine 6 (His6)-AP sequence of pAP-6. To express AP-NgR, plasmid was transfected into HEK293T cells, and conditioned medium was collected after $4 \mathrm{~d}$. Secreted protein was purified by $\mathrm{Ni}^{2+}$ affinity chromatography (Nakamura et al., 1998). AP-Nogo or AP-NgR binding in COS-7 cells was assessed as described previously (Takahashi et al., 1998; Fournier et al., 2001).

Growth cone collapse and neurite outgrowth assays. Preparation of embryonic day 7 (E7) chick retinal explant cultures and recombinant HSV preparations have been described in detail previously (Fournier et al., 2000a). Retinal explants were grown for $12 \mathrm{hr}$ and then incubated for an additional $24 \mathrm{hr}$ with HSVNgR preparations. Explants were treated for $30 \mathrm{~min}$ with $0,50,250$, or $500 \mathrm{~nm}$ glutathione $S$-transferase (GST) Nogo-66 (GrandPre et al., 2000), fixed, and stained with phalloidin (Molecular Probes, Eugene, OR). Growth cone collapse was assayed as described previously (Luo et al., 1993). For neurite outgrowth assays on Nogo, myelin, or aggrecan substrates, Permanox chamber slides (Fisher Scientific, Pittsburgh, PA) were coated with $100 \mu \mathrm{g} / \mathrm{ml}$ poly-L-lysine and washed, and then $3 \mu \mathrm{l}$ drops of PBS containing 0,50 , or $150 \mathrm{ng}$ of GSTNogo-66, myelin, or aggrecan with or without $500 \mathrm{ng}$ of NgREcto were spotted and dried. After three PBS washes, slides were coated with $10 \mu \mathrm{g} / \mathrm{ml}$ laminin. Dissociated E13 chick dorsal root ganglia (DRG) neurons were grown for $4-8 \mathrm{hr}$, fixed, and stained with phalloidin, and neurite outgrowth lengths were assessed using NIH Image. GSTNogo-66 and myelin were prepared as described previously (Fournier et al., 2000b; GrandPre et al., 2000). Aggrecan was obtained from Sigma (St. Louis, $\mathrm{MO})$.

Analysis of membrane fractions on flotation gradients. HEK293T cells were cultured in $6 \mathrm{~cm}$ culture dishes and transfected with HSVWTNgR or HSVNgRL1 plasmids. After $48 \mathrm{hr}$, cells were rinsed with PBS and then lysed on ice with $375 \mu$ l precooled TNE buffer (in mM: 50 Tris- $\mathrm{HCl}$, $\mathrm{pH} 7.4,150 \mathrm{NaCl}$, and 5 EDTA) containing $0.1 \%$ Triton X-100, $10 \mathrm{~mm}$ $\mathrm{NaF}$, and protease inhibitors (TNEX). Cells were homogenized by passing the ice-cold lysates through a 27 gauge needle 10 times. Extracts were adjusted to $35 \%$ OptiPrep (Invitrogen, Gaithersburg, MD) by adding $525 \mu \mathrm{l}$ of $60 \%$ OptiPrep- $0.1 \%$ Triton $\mathrm{X}-100$, placed in an ultracentrifuge tube, and overlaid with $8.75 \mathrm{ml}$ of $30 \%$ OptiPrep in TNEX and $1 \mathrm{ml}$ of TNEX. After centrifugation $\left(4 \mathrm{hr} ; 200,000 \times g ; 4^{\circ} \mathrm{C}\right)$, seven fractions were collected, precipitated in TCA, washed with acetone, air dried, and resuspended in Laemmli's sample buffer. Fractions were analyzed by $8 \%$ SDS-PAGE and immunoblotting with the $\mathrm{NgR}$ antibody (Fournier et al., 2001). For detection of transferrin receptor, a mouse monoclonal antibody (Zymed, San Francisco, CA) was used. 

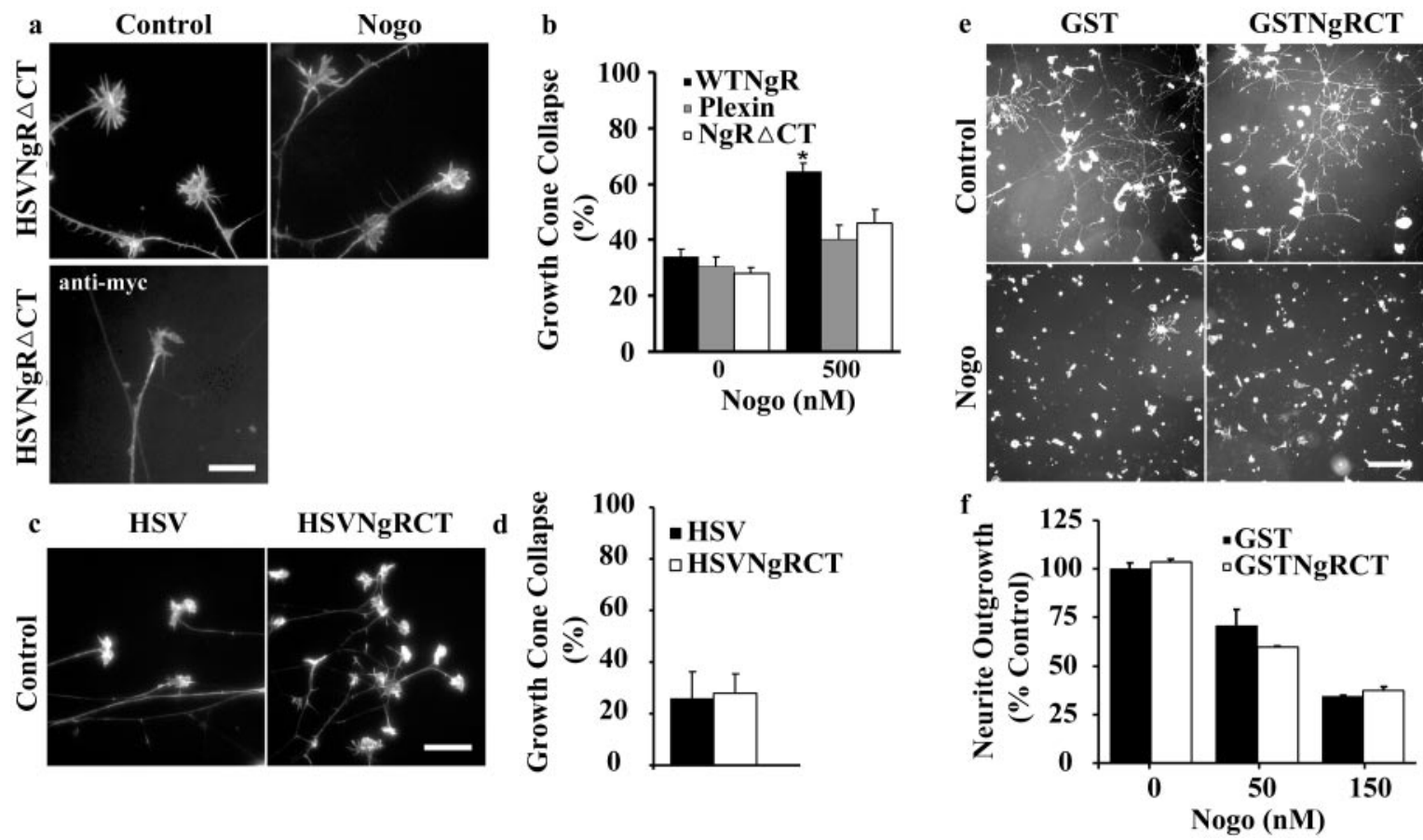

Figure 2. The CT region of $\mathrm{NgR}$ is necessary but not sufficient for Nogo inhibition. $a$, E7 retinal explants were infected with a recombinant viral preparation of the $\mathrm{NgR} \Delta \mathrm{CT}$. NgR $\Delta \mathrm{CT}$-infected RGCs were insensitive to a 40 min treatment with $500 \mathrm{~nm}$ GSTNogo-66. Expression of NgR $\Delta \mathrm{CT}$ in RGC neurites and growth cones was verified by Myc immunostaining. Scale bar, $50 \mu \mathrm{m}$. $b$, Quantification of the growth cone collapse response of RGCs to GSTNogo-66 after viral infection with $\mathrm{NgR} \Delta \mathrm{CT}$, WTNgR, or a control plexinA1 virus (Plexin). Means \pm SEM from 4-10 experiments are reported. Student's $t$ tests comparing WTNgR or NgR $\Delta$ CT to control plexinA1 values at the indicated Nogo concentration are reported. * $p<0.001 . c$, E7 RGC explants were infected with recombinant viral preparations of control HSV particles (HSV) or HSV $\mathrm{NgRCT}$. NgRCT alone does not cause growth cone collapse. Scale bar, $100 \mu \mathrm{m}$. $d$, Quantification of E7 RGC growth cone collapse after control HSV or HSV NgRCT infection. Means \pm SEM for three experiments are reported. $e$, Neurite outgrowth of dissociated E13 DRGs plated on control or Nogo substrates and treated with 500 nM soluble GST or GSTNgRCT. GSTNgRCT does not inhibit neurite outgrowth on control spots or modify the response of E13 DRGs to Nogo inhibition. Scale bar, 200 $\mu \mathrm{m} . f$, Nogo dose-response of E13 DRG neurite outgrowth in the presence of GST or GSTNgRCT. Neurite outgrowth is calculated as micrometers of growth per cell. Means \pm SEM from three experiments are reported.

Caveolin was detected with a rabbit polyclonal antibody (Upstate Biotechnology, Lake Placid, NY).

\section{RESULTS}

\section{Leucine-rich repeats are required for AP-Nogo binding}

To better understand structure-function relationships for the $\mathrm{NgR}$, deletion mutants were generated and tested for Nogo binding. NgR contains a signal sequence, an LRR-type N-terminal region (LRRNT) (Pfam accession number PF01462), eight LRR domains (LRR1-8) (Pfam accession number PF00560), an LRRtype C-terminal domain (LRRCT) (Pfam accession number PF01463), a unique C-terminal domain, and a GPI linkage domain (Fournier et al., 2001). Domains of the NgR were systematically deleted using PCR-based site-directed mutagenesis (Fig. 1a). Individual $\mathrm{NgR}$ mutants expressed in COS-7 cells exhibit the predicted mobility as verified by Myc immunoblots (data not shown). The ability of individual $\mathrm{NgR}$ mutants to bind to Nogo-66 was assessed using an AP-Nogo binding assay (Fournier et al., 2001). COS-7 cells were transfected with individual $\mathrm{NgR}$ deletion mutant constructs, treated with AP or AP-Nogo conditioned medium, and assayed for AP binding. AP-Nogo binding was detected in WTNgR or NgR $\Delta \mathrm{CT}$ (Fig. $1 b$ ). NgR deleted in any pair of the LRRs (NgR $\Delta 1-2, \operatorname{NgR} \Delta 3-4, \mathrm{NgR} \Delta 5-6$, $\mathrm{NgR} \Delta 7-8$, and $\mathrm{NgRLRR}-$ ) or in the N-terminal or LRR-type C-terminal flanking regions of the LRRs ( $\mathrm{NgR} \Delta \mathrm{NT}$ and NgR $\Delta$ LRRCT, respectively) does not support AP-Nogo binding. The AP-Nogo binding pattern suggests that dispersed amino acid residues within the NgR LRR region are required for AP-Nogo binding. Alternatively, mutations in individual LRR regions may disrupt the tertiary structure of the $\mathrm{NgR}$, resulting in a loss of AP-Nogo binding. For other LRR-containing receptors, similar deletions do not disrupt the function of remaining repeats (Song et al., 2001a,b), suggesting that multiple LRRs participate directly in Nogo-66 binding.

\section{NgRCT domain is required but not sufficient for NgR-dependent inhibition}

Although the $\mathrm{NgRCT}$ domain is not required for Nogo binding, we considered the possibility that it participates in Nogodependent inhibition of axon growth. E7 retinal ganglion cells (RGCs) were infected with recombinant HSVNgR $\Delta$ CT preparations, and growth cone collapse in response to GSTNogo-66 was assessed (Fig. 2a,b). Under these conditions, wild-type NgR supports Nogo-66-dependent growth cone collapse. RGCs infected with $\mathrm{NgR} \Delta \mathrm{CT}$ are not sensitive to Nogo in the growth cone collapse assay. The $\mathrm{CT}$ region of $\mathrm{NgR}$ is therefore required for effective $\mathrm{NgR}$ inhibitory signaling.

One possibility is that the $\mathrm{CT}$ domain of $\mathrm{NgR}$ binds to a transducing receptor component to initiate an intracellular signaling cascade after ligand binding. This would explain why $\mathrm{NgR}$ deleted in the $\mathrm{CT}$ region is signaling incompetent. If this were the case, it is also possible that the $\mathrm{CT}$ region of $\mathrm{NgR}$ is capable of constitutive receptor activity. To test this possibility, recombinant viral preparations expressing GPI-anchored $\mathrm{NgRCT}$ were used to 


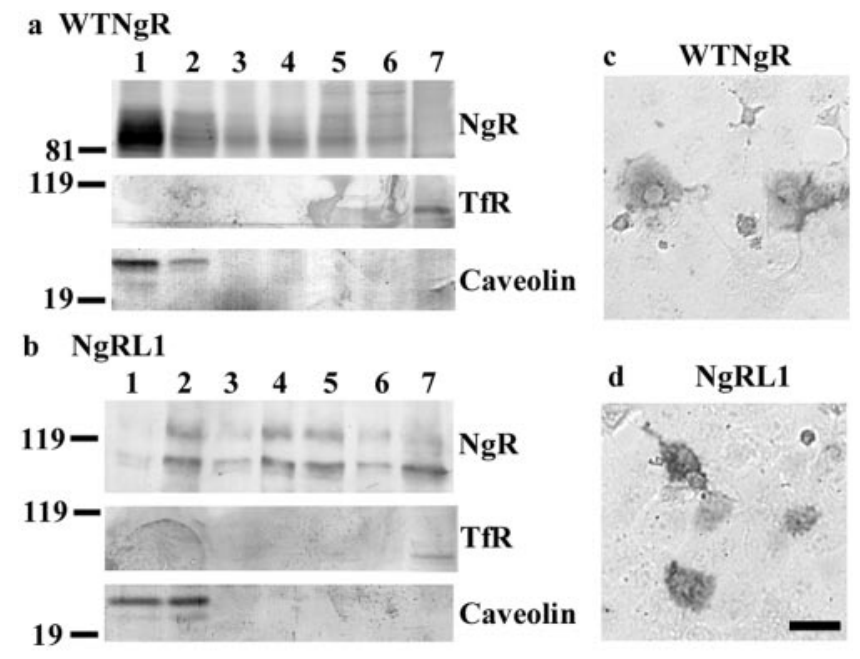

Figure 3. Characterization of NgRL1. a, Cell lysates from HEK293T cells transfected with HSVWTNgR or HSV NgRL1 plasmids were fractionated on flotation gradients. WTNgR is found almost exclusively in the caveolin-positive detergent-insoluble fraction. $b$, NgRL1 is in multiple membrane fractions, with a small proportion in the caveolin-positive detergent-insoluble fraction. $c$, COS-7 cells were transfected with WTNgR and tested for $10 \mathrm{~nm}$ AP-Nogo binding. $d$, COS-7 cells were transfected with NgRL1 and tested for $10 \mathrm{~nm}$ AP-Nogo binding. Cells expressing WTNgR or NgRL1 bind similar amounts of AP-Nogo. Scale bar, $100 \mu \mathrm{m}$.

infect E7 RGCs (Fig. 2c,d). Expression of NgRCT does not cause growth cone collapse in infected RGCs. In a second assay, NgRCT was purified as a soluble GST fusion protein (GSTNgRCT) and tested for its ability to disrupt signaling in a dominant negative manner. E13 chick DRGs were dissociated and plated in the presence or absence of $500 \mathrm{~nm}$ soluble GST or GSTNgRCT. In this assay, GSTNogo-66 inhibits neurite outgrowth (Fournier et al., 2001). Soluble GSTNgRCT does not alter neurite outgrowth lengths on control substrates, nor does it attenuate or enhance the response of dissociated E13 DRGs on Nogo substrates (Fig. 2e,f). Together, these experiments indicate that the $\mathrm{CT}$ region of $\mathrm{NgR}$ is necessary but not sufficient for $\mathrm{NgR}$-dependent inhibition.

\section{$\mathrm{NgR}$ GPI domain is not required for $\mathrm{NgR}$ signaling}

In some cases, GPI anchors are critical for receptor function. The GPI anchor of GDNF receptor- $\alpha 1$ (GFR $\alpha 1)$ plays a critical role in localizing receptor components to lipid rafts and permitting receptor tyrosine kinase (RET) activation (Tansey et al., 2000). To assess the role of the GPI anchor in mediating inhibitory Nogo signals, a chimeric $\mathrm{NgR}$ was generated by exchanging the $\mathrm{NgR}$ GPI domain with the transmembrane domain of the L1 cell adhesion molecule (Nieke and Schachner, 1985) in a pHSVPrPUC vector (HSVNgRL1). GPI-linked proteins localize to detergent-insoluble sphingolipid and cholesterol-rich lipid microdomains that exist as phase-separated "lipid rafts" in the plasma membrane (Simons and Ikonen, 1997; Brown and London, 1998). Sphingolipids and cholesterol in cell membranes are resistant to solubilization with nonionic detergents at $4^{\circ} \mathrm{C}$, allowing lipid rafts to be isolated as detergent-resistant membrane fractions (Brown and Rose, 1992).

HEK293T cells were transfected with HSVWTNgR or HSVNgRL1, and membrane fractionation on flotation gradients was performed (Fig. 3). As expected for a GPI-anchored protein, WTNgR localizes primarily to the caveolin-positive lipid raft

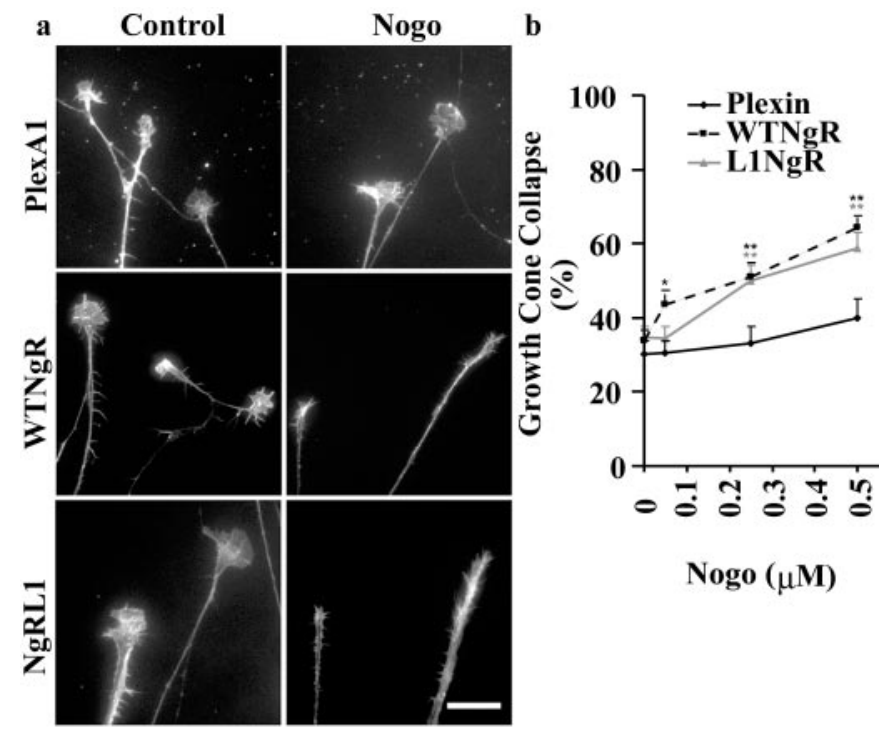

Figure 4. The GPI linkage region of $\mathrm{NgR}$ is not required for Nogomediated inhibition. $a$, E7 retinal explants were infected with recombinant viral preparations of PlexA1, WTNgR, or NgRL1. Explants were treated with $500 \mathrm{~nm}$ GSTNogo-66 for $40 \mathrm{~min}$, fixed, and stained with rhodamine-phalloidin. RGCs infected with PlexA1 control virus are insensitive to Nogo, whereas those infected with WTNgR or NgRL1 collapse in response to Nogo. Scale bar, $50 \mu \mathrm{m}$. $b$, Dose-response of RGCs to GSTNogo-66 after infection with NgR viral preparations. Student's $t$ tests comparing WTNgR or NgRL1 to PlexA1 at the indicated Nogo concentration are reported. ${ }^{*} p=0.01 ; *{ }^{*} p<0.01$. Significance indicators $(*)$ are coded with the appropriate infection. Means \pm SEM for 6-10 experiments are reported.

fractions. In contrast, the vast majority of chimeric NgRL1 localizes to the caveolin-negative fractions, and the small proportion cosedimenting with caveolin is likely to reflect incomplete separation rather than any raft localization. The ability of $\mathrm{NgRL} 1$ to bind to Nogo with an affinity similar to that of the WTNgR was verified by assaying AP-Nogo binding in transfected COS-7 cells (Fig. $3 c, d$ ). To test the signaling capability of $\mathrm{NgRL1}$, recombinant HSV NgRL1 preparations were produced and used to infect E7 RGCs. Infected RGCs were treated with GSTNogo-66, and growth cone collapse was assessed (Fig. 4). At high concentrations of Nogo, NgRL1 transduces Nogo signals as efficiently as WTNgR. However, a 50 nm Nogo dose collapses RGC growth cones infected with WTNgR, whereas NgRL1-infected RGCs are unresponsive. Therefore, NgRL1 mediates Nogo signaling less efficiently than WTNgR. The GPI anchorage site may play a modulatory role in Nogo signaling.

\section{$\mathrm{NgR}$ binds $\mathrm{NgR}$}

One hypothesis for the diminished signaling efficiency of NgRL1 is that NgRL1 fails to concentrate in lipid rafts, and the consequent loss of receptor clustering leads to inefficient Nogo signaling. To consider this possibility, we determined whether $\mathrm{NgR}$ was capable of interacting with itself. COS-7 cells were transfected with WTNgR or NgR deletion mutant plasmids and stained with AP-NgR conditioned medium (Fig. 5). Clearly, the extracellular domain of $\mathrm{NgR}$ has significant affinity for surface-bound $\mathrm{NgR}$. Binding saturation was difficult to achieve reliably; however, the $K_{\mathrm{d}}$ of this interaction is estimated to be $\geq 50 \mathrm{~nm}$. Considering that endogenous $\mathrm{NgR}$ molecules are likely to interact in cis within lipid rafts, this affinity is consistent with physiological relevance. Analysis of AP-NgR binding to $\mathrm{NgR}$ deletion mutants reveals 


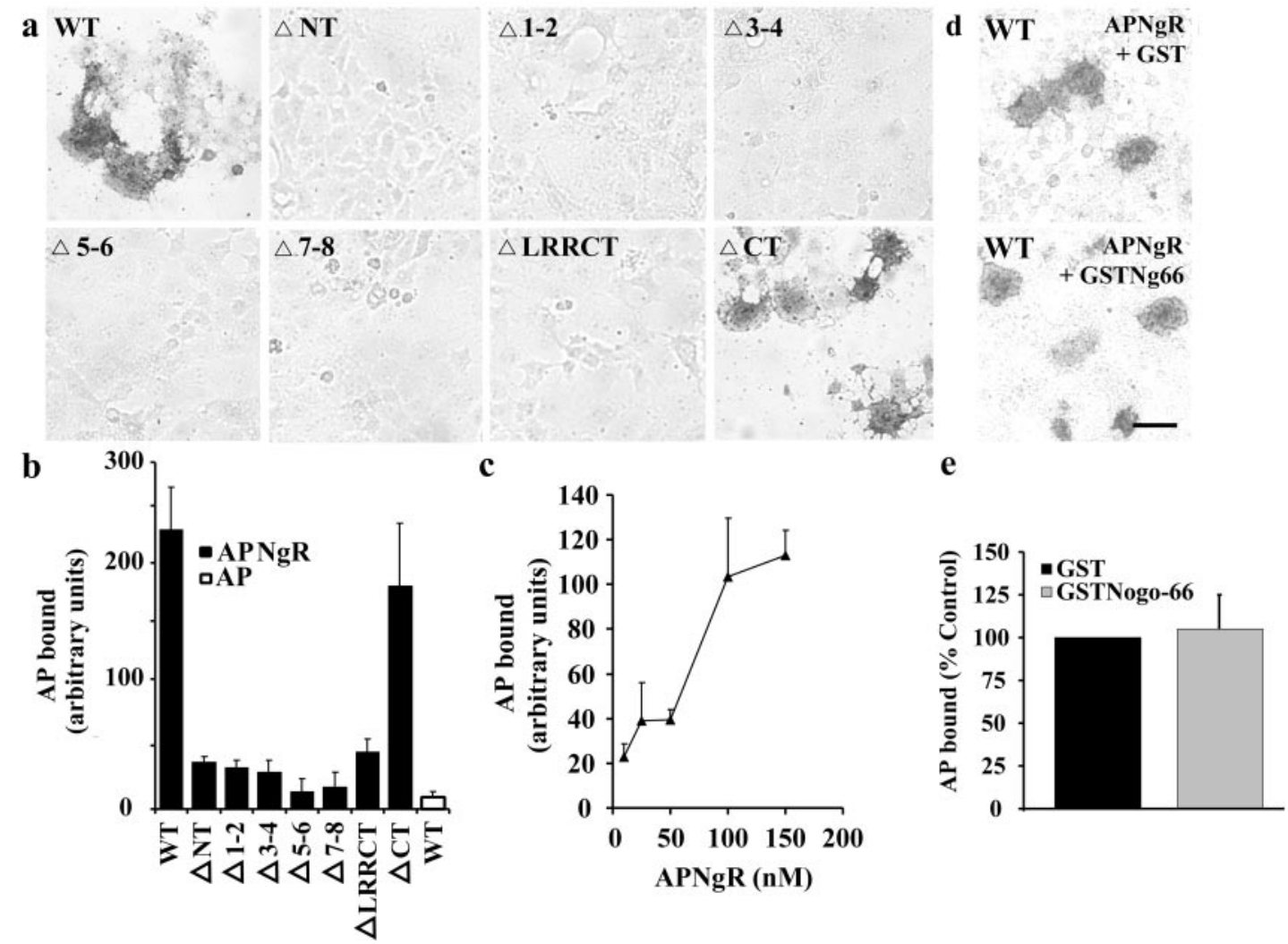

Figure 5. $\mathrm{NgR}$ interacts with itself. $a$, COS-7 cells were transfected with WTNgR or NgR deletion mutant plasmids and tested for AP or AP-NgR binding. WTNgR- and NgR $\Delta$ CT-transfected COS-7 cells bind to AP-NgR. $b$, Quantification of AP or AP-NgR binding to COS-7 cells transfected with $\mathrm{NgR}$ deletion mutants. $c$, AP-NgR binding to COS-7 cells transfected with NgR as a function of AP-NgR concentration. Mean \pm SEM for three experiments. $d$, COS-7 cells were transfected with WTNgR and treated with AP-NgR in the presence of 25 nM GST or GSTNogo-66 (GSTNg66). AP-NgR interaction with WTNgR is not modified by the presence of GST or GSTNogo-66. Scale bar, $100 \mu$ m. $e$, Quantification of AP-NgR binding to WTNgR-transfected COS-7 cells in the presence of 25 nM GST or GSTNogo-66.

that the receptor multimerization domain, like the Nogo-66 binding site (Fig. 1), is localized to the LRR domains.

Receptor multimerization does not appear to be regulated by ligand. First, the presence of Nogo has little, if any, effect on AP-NgR binding to NgR-transfected COS-7 cells (Fig. 5b). Second, when transfected HEK293T cells were treated with Nogo, the membrane fractionation profile of WTNgR and NgRL1 remained unchanged (data not shown). This suggests that Nogo does not modulate NgR localization to lipid raft compartments in HEK293T cells. It should be noted that both of these assays were performed in non-neuronal cell lines. It is possible that Nogo affects $\mathrm{NgR}$ multimerization in neurons that may possess additional components required for Nogo signaling. It is also possible that ligand binding modifies the localization of additional unidentified signaling components within the lipid raft, as is the case for ephrins (Davy et al., 1999). Because the components of the $\mathrm{NgR}$ intracellular signaling cascade have not been identified, the effect of Nogo on the recruitment of signaling components to lipid rafts remains an open question.

\section{Truncated NgR antagonizes Nogo and myelin-dependent inhibition}

On the basis of the structure-function analysis of $\mathrm{NgR}$, a truncated soluble $\mathrm{NgR}$ (NgREcto) was assayed for antagonism of Nogo-66 signaling. NgREcto consists of residues 1 through 310, which includes the entire binding region for Nogo-66, but lacks the $\mathrm{NgRCT}$ region that is required for $\mathrm{NgR}$ signaling and the GPI linkage region of the receptor. $\mathrm{NgREcto}$ protein was purified from the conditioned medium of stably transfected $\mathrm{CHO}$ cells. The ability of NgREcto to antagonize Nogo-NgR interactions was tested by treating WTNgR-expressing COS-7 cells with $7 \mathrm{nM}$ Nogo-AP in the presence or absence of $70 \mathrm{~nm} \mathrm{NgREcto} \mathrm{(Fig.}$ $6 a, b)$. NgREcto significantly reduces Nogo-AP binding to transfected cells. To test the effect of NgREcto on signaling through the NgR, E13 dissociated DRGs were plated on mixed NgREctoNogo-66 substrates (Fig. $6 c, d$ ). Neurite outgrowth from E13 chick DRGs plated on GSTNogo-66 substrates without NgREcto is strongly inhibited. NgREcto to a great extent reverses this neurite outgrowth inhibition by Nogo. NgREcto is unable to overcome the inhibitory activity of the chondroitin sulfate proteoglycan aggrecan (Seidenbecher et al., 1998), suggesting that the $\mathrm{NgRE}$ cto reagent is acting specifically on the $\mathrm{NgR}$ pathway. Because bound $\mathrm{NgREcto}$ might alter the surface properties of the laminin-Nogo substrate, purified NgREcto was also applied as a soluble protein to test for its ability to antagonize Nogo inhibition (Fig. 6f). The inhibitory effect of Nogo-66 is significantly diminished in the presence of $2 \mu \mathrm{M}$ soluble $\mathrm{NgRE}$ cto protein.

$\mathrm{NgRE}$ cto is a specific Nogo-66 antagonist; therefore, the relative importance of Nogo-66 in inhibition of axon outgrowth by CNS myelin can be assessed. When the same protocol is used as for GSTNogo-66, myelin strongly inhibits chick E13 DRG neurite outgrowth. $\mathrm{NgRE}$ eto blocks a significant proportion of this inhib- 


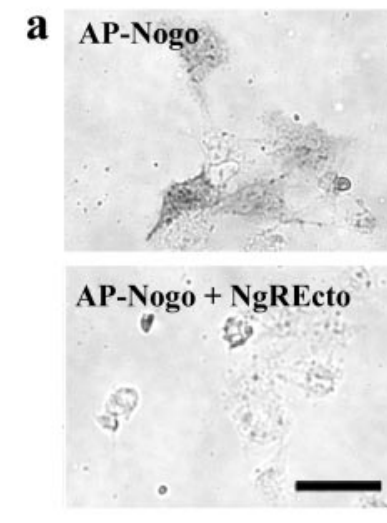

b

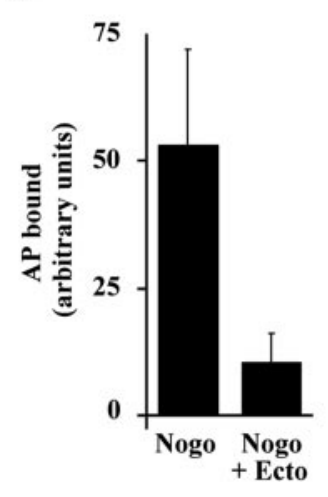

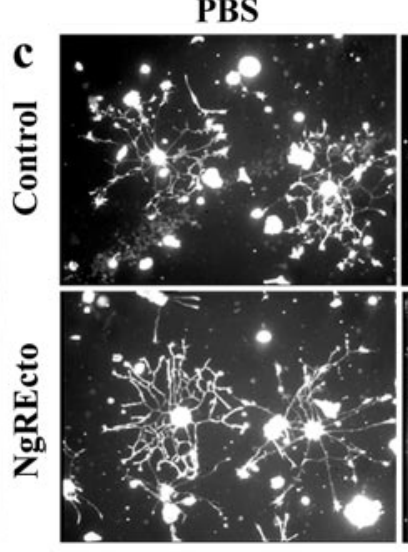

d

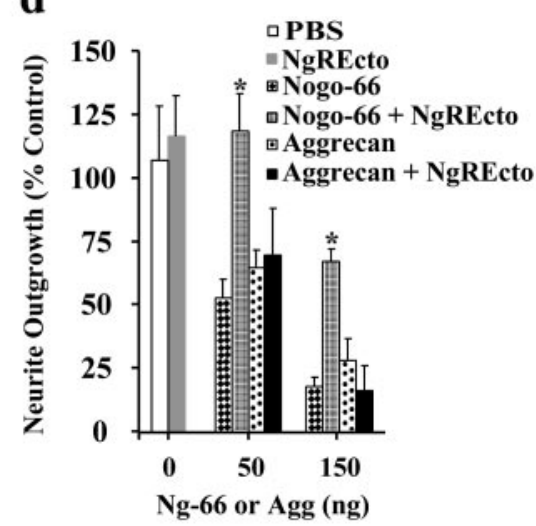

PBS
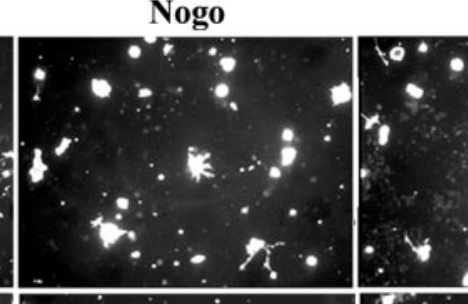

Myelin
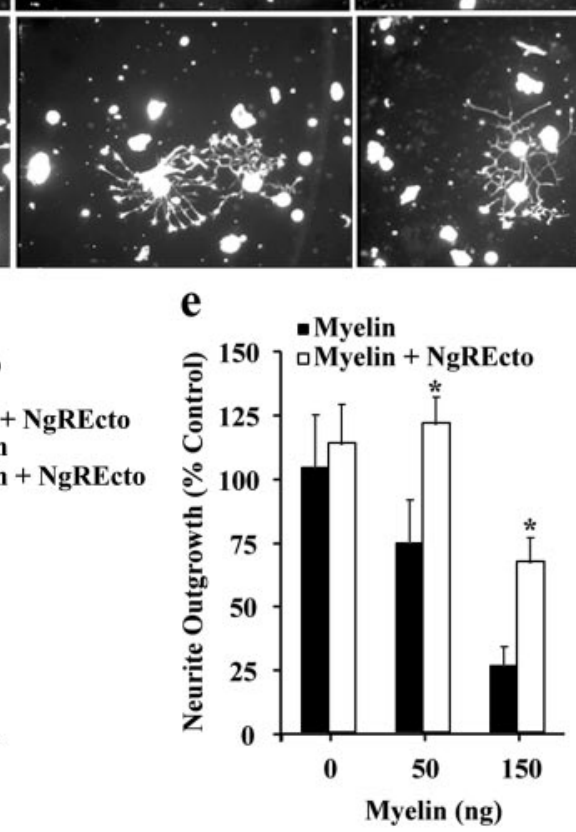

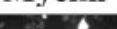

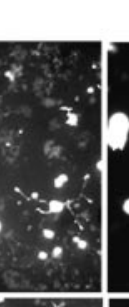

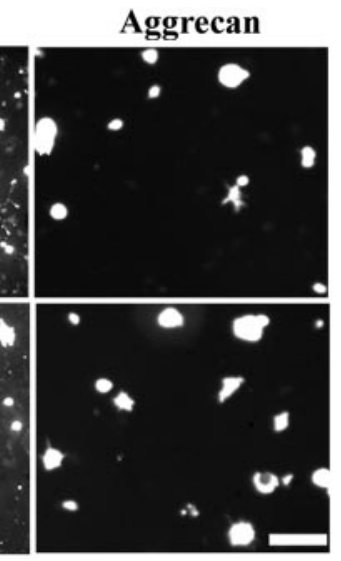

f

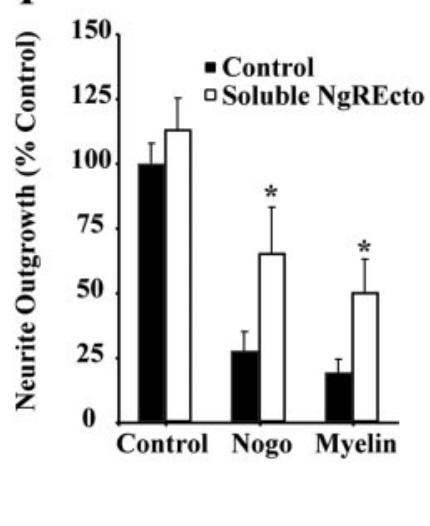

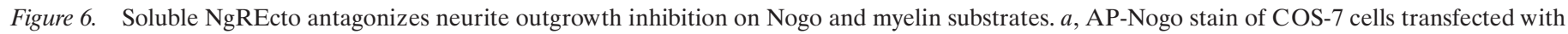

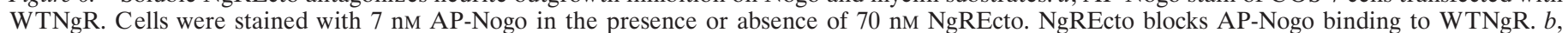

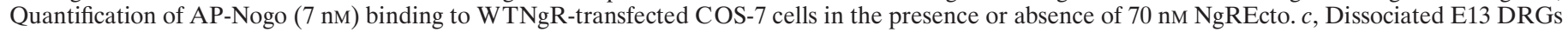

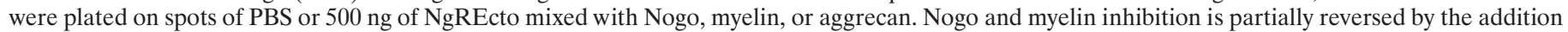

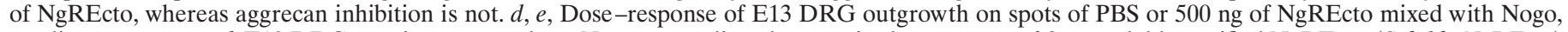

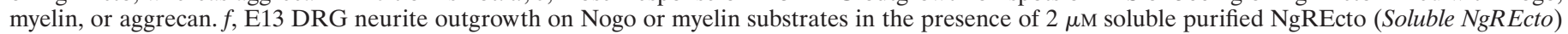

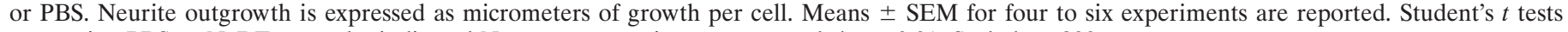
comparing PBS to NgREcto at the indicated Nogo concentration are reported. ${ }^{*} p<0.01$. Scale bar, $200 \mu \mathrm{m}$.

itory activity (Fig. $6 c, e, f$ ), consistent with the notion that $\mathrm{NgR}$ plays a primary role in mediating myelin action.

\section{DISCUSSION}

Previous studies have identified $\mathrm{NgR}$ as a highly potent, biologically active receptor for Nogo-66 (Fournier et al., 2001). By generating $\mathrm{NgR}$ deletion mutants and chimeric receptors, we demonstrate that the entire LRR region of $\mathrm{NgR}$ is required for Nogo binding to $\mathrm{NgR}$ and that the CT region of $\mathrm{NgR}$ is necessary but not sufficient for inhibitory $\mathrm{NgR}$ signaling (Fig. 7). Furthermore, the GPI linkage is not critical for NgR signaling but may modulate the efficacy of $\mathrm{NgR}$-dependent inhibition. We have also identified a soluble, truncated form of $\mathrm{NgR}$ that can antagonize the inhibitory effects of Nogo or myelin on E13 chick DRG outgrowth. This supports a central role for $\mathrm{NgR}$ in myelin inhibition of axon growth.

\section{Role of NgR LRR and CT domains}

It is clear that the LRR domains of $\mathrm{NgR}$ are required for binding to Nogo. Because the NgRCT region is not sufficient to induce inhibition, it is likely that the LRR domains contribute to additional aspects of inhibitory signaling. The LRR region can also bind to full-length $\mathrm{NgR}$; therefore, this domain may regulate receptor oligomerization and/or bind to an unidentified signal- transducing receptor subunit. The greatest sequence similarity in the NgR LRR region exists with Slit 1-3 and the acid-labile subunit of the insulin-like growth factor-binding protein complex. Slits are a family of extracellular matrix proteins that are expressed at the developing CNS midline and repel axons via receptors of the Roundabout (Robo) family (Brose et al., 1999; Zinn and Sun, 1999). The Slit LRRs have been shown recently to mediate binding to Robo and repellent signaling (Battye et al., 2001). Thus, the Slit-Robo interaction may provide a model for $\mathrm{NgR}$ interaction with a signal-transducing protein.

The unique CT domain of the $\mathrm{NgR}$ is required for $\mathrm{NgR}$ dependent inhibition. The most plausible model is that this domain participates directly in the activation of a transmembrane signal-transducing component of the $\mathrm{NgR}$. However, its inability to act in a constitutively active manner raises the possibility that the CT domain may facilitate $\mathrm{NgR}$ conformational changes that lead to axon inhibition by the LRR domain.

\section{Role of the NgR GPI anchor}

The GPI anchor is not absolutely required for $\mathrm{NgR}$ inhibitory signaling, because chimeric NgRL1 mediates Nogo-66-induced growth cone collapse when expressed in RGCs. The GPI anchor site could modulate the efficacy of $\mathrm{NgR}$ signaling by concentrating 


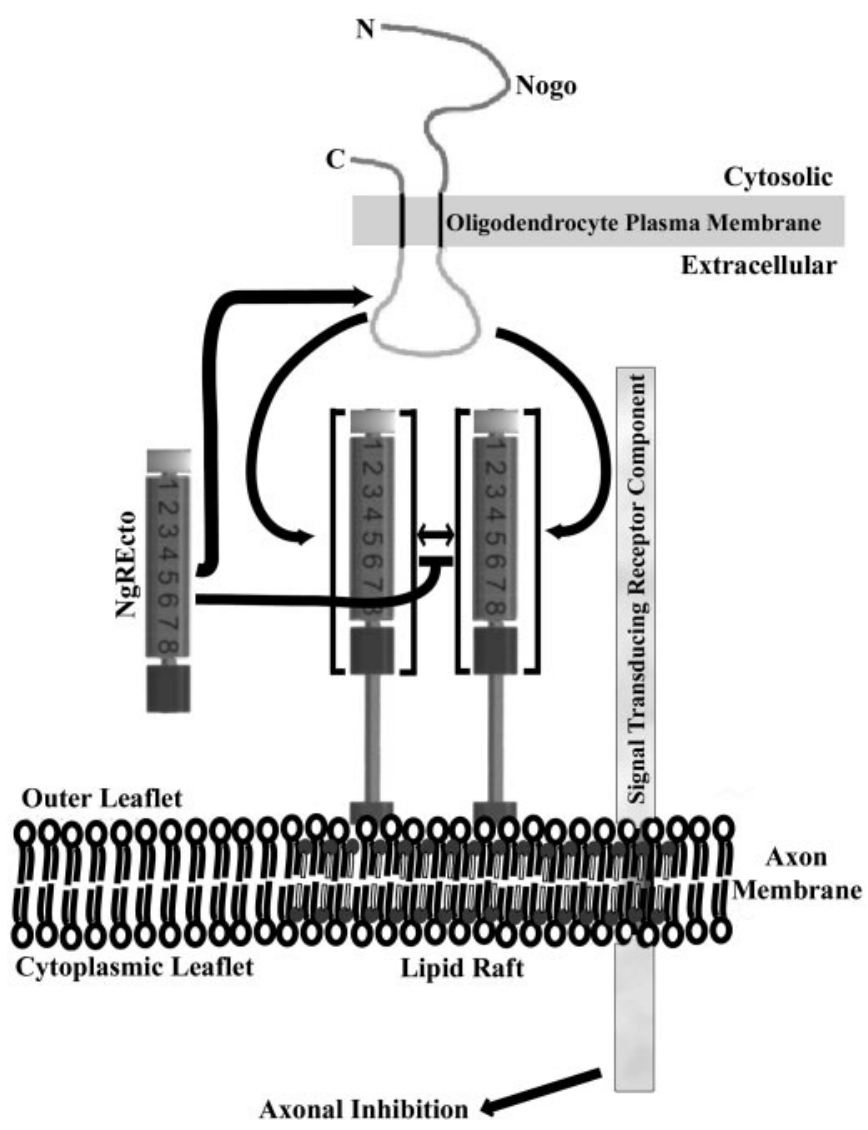

Figure 7. Model of Nogo receptor-mediated signaling. This schematic illustrates the proposed role each Nogo receptor domain plays in Nogosignal transduction. See Discussion.

$\mathrm{NgR}$ in lipid rafts. The importance of raft localization of receptors is clear for the GDNF receptors GFR $\alpha 1-$ GFR $\alpha 4$. GFR $\alpha 1-$ GFR $\alpha 4$ are GPI-anchored receptors that are responsible for providing specific high-affinity binding sites for individual GDNF family ligands (GFL). All GFRs interact with a common receptor tyrosine kinase, RET (Tansey et al., 2000), that signals intracellularly via its cytoplasmic kinase domain. The GPI anchor plays a critical role in the GFL signaling pathway by restricting GFR $\alpha 1$ protein to lipid rafts, where RET is recruited after GDNF family ligand binding. GFR $\alpha 1$-mediated RET recruitment to the lipid raft is critical for efficient GFL signaling. Lipid rafts are thought to represent specialized signaling compartments within the plasma membrane because of the enrichment of Src family kinases and other signaling proteins that localize to the intracellular leaflet of lipid rafts (Anderson, 1998). The GPI anchor of the $\mathrm{NgR}$ could regulate the efficiency of $\mathrm{NgR}$ signaling by restricting its localization within the plasma membrane. This restricted distribution might enhance $\mathrm{NgR}$ multimerization and access to downstream signaling molecules.

It is also plausible that the role of the NgR GPI linkage is to provide an NgR cleavage site. Although there is as yet no evidence that truncated soluble $\mathrm{NgR}$ exists in vivo, it is clear that NgREcto is capable of antagonizing myelin inhibition. Released $\mathrm{NgR}$ might modulate Nogo signaling by loss of surface NgR from one axon and by diffusible blockade of $\mathrm{NgR}$ action.

\section{NgREcto reverses Nogo signaling}

The NgREcto protein contains a Nogo-66 binding site and blocks Nogo-66 action. Soluble NgREcto may bind to Nogo and prevent its binding to full-length active Nogo receptors on the neuronal cell surface. Alternatively, NgREcto might interact with surfacebound axonal $\mathrm{NgR}$ and prevent receptor oligomerization or $\mathrm{NgR}$ interaction with a signal-transducing receptor subunit (Fig. 7). The affinity of AP-Nogo is fivefold to 10-fold higher than AP$\mathrm{NgR}$ for surface-bound $\mathrm{NgR}$. Therefore, it is likely that $\mathrm{NgRE}$ eto acts primarily by disrupting ligand-receptor interactions.

\section{NgR mediates myelin inhibition}

Previous work had not clarified the relative role of myelin-derived inhibitors on axon growth or the role of different Nogo domains. The ability of NgREcto to reverse a majority of myelin-dependent inhibition of axon growth demonstrates that the Nogo-66 receptor is a primary mediator of myelin action. Furthermore, the $\mathrm{NgREcto}$ protein is a potential therapeutic agent to promote axon regeneration in the injured adult CNS.

\section{REFERENCES}

Anderson RG (1998) The caveolae membrane system. Annu Rev Biochem 67:199-225.

Battye R, Stevens A, Perry RL, Jacobs JR (2001) Repellent signaling by Slit requires the leucine-rich repeats. J Neurosci 21:4290-4298.

Brose K, Bland KS, Wang KH, Arnott D, Henzel W, Goodman CS, Tessier-Lavigne M, Kidd T (1999) Slit proteins bind Robo receptors and have an evolutionarily conserved role in repulsive axon guidance. Cell 96:795-806.

Brown DA, London E (1998) Functions of lipid rafts in biological membranes. Annu Rev Cell Dev Biol 14:111-136.

Brown DA, Rose JK (1992) Sorting of GPI-anchored proteins to glycolipid-enriched membrane subdomains during transport to the apical cell surface. Cell 68:533-544.

Buchanan SG, Gay NJ (1996) Structural and functional diversity in the leucine-rich repeat family of proteins. Prog Biophys Mol Biol 65:1-44.

Caroni P, Schwab ME (1988a) Two membrane protein fractions from rat central myelin with inhibitory properties for neurite growth and fibroblast spreading. J Cell Biol 106:1281-1288.

Caroni P, Schwab ME (1988b) Antibody against myelin-associated inhibitor of neurite growth neutralizes nonpermissive substrate properties of CNS white matter. Neuron 1:85-96.

Chen MS, Huber AB, van der Haar ME, Frank M, Schnell L, Spillmann AA, Christ F, Schwab ME (2000) Nogo-A is a myelin-associated neurite outgrowth inhibitor and an antigen for monoclonal antibody IN-1. Nature 403:434-439.

Davy A, Gale NW, Murray EW, Klinghoffer RA, Soriano P, Feuerstein C, Robbins SM (1999) Compartmentalized signaling by GPIanchored ephrin-A5 requires the Fyn tyrosine kinase to regulate cellular adhesion. Genes Dev 13:3125-3135.

Fournier AE, Kalb RG, Strittmatter SM (2000a) Rho GTPases and axonal growth cone collapse. Methods Enzymol 325:473-482.

Fournier AE, Nakamura F, Kawamoto S, Goshima Y, Kalb RG, Strittmatter SM (2000b) Semaphorin3A enhances endocytosis at sites of receptor-F-actin colocalization during growth cone collapse. J Cell Biol 149:411-422.

Fournier AE, GrandPre T, Strittmatter SM (2001) Identification of a receptor mediating Nogo-66 inhibition of axonal regeneration. Nature 409:341-346.

GrandPre T, Nakamura F, Vartanian T, Strittmatter SM (2000) Identification of the Nogo inhibitor of axon regeneration as a reticulon protein. Nature 403:439-444.

Luo Y, Raible D, Raper JA (1993) Collapsin: a protein in brain that induces the collapse and paralysis of neuronal growth cones. Cell 75:217-227.

McKerracher L, David S, Jackson DL, Kottis V, Dunn RJ, Braun PE (1994) Identification of myelin-associated glycoprotein as a major myelin-derived inhibitor of neurite growth. Neuron 13:805-811.

Mukhopadhyay G, Doherty P, Walsh FS, Crocker PR, Filbin MT (1994) A novel role for myelin-associated glycoprotein as an inhibitor of axonal regeneration. Neuron 13:757-767.

Nakamura F, Tanaka M, Takahashi T, Kalb RG, Strittmatter SM (1998) Neuropilin-1 extracellular domains mediate semaphorin D/III-induced growth cone collapse. Neuron 21:1093-1100.

Niederost BP, Zimmermann DR, Schwab ME, Bandtlow CE (1999) Bovine CNS myelin contains neurite growth-inhibitory activity associated with chondroitin sulfate proteoglycans. J Neurosci 19:8979-8989.

Nieke J, Schachner M (1985) Expression of the neural cell adhesion molecules L1 and N-CAM and their common carbohydrate epitope L2/HNK-1 during development and after transection of the mouse sciatic nerve. Differentiation 30:141-151.

Prinjha R, Moore SE, Vinson M, Blake S, Morrow R, Christie G, 
Michalovich D, Simmons DL, Walsh FS (2000) Inhibitor of neurite outgrowth in humans. Nature 403:383-384.

Schnell L, Schwab ME (1990) Axonal regeneration in the rat spinal cord produced by an antibody against myelin-associated neurite growth inhibitors. Nature 343:269-272.

Seidenbecher CI, Gundelfinger ED, Bockers TM, Trotter J, Kreutz MR (1998) Transcripts for secreted and GPI-anchored brevican are differentially distributed in rat brain. Eur J Neurosci 10:1621-1630.

Simons K, Ikonen E (1997) Functional rafts in cell membranes. Nature 387:569-572.

Song YS, Ji I, Beauchamp J, Isaacs NW, Ji TH (2001a) Hormone interactions to Leu-rich repeats in the gonadotropin receptors. I. Analysis of Leu-rich repeats of human luteinizing hormone/chorionic gonadotropin receptor and follicle-stimulating hormone receptor. J Biol Chem 276:3426-3435.

Song YS, Ji I, Beauchamp J, Isaacs NW, Ji TH (2001b) Hormone inter- actions to Leu-rich repeats in the gonadotropin receptors. II. Analysis of Leu-rich repeat 4 of human luteinizing hormone/chorionic gonadotropin receptor. J Biol Chem 276:3436-3442.

Takahashi T, Nakamura F, Jin Z, Kalb RG, Strittmatter SM (1998) Semaphorins A and E act as antagonists of neuropilin-1 and agonists of neuropilin-2 receptors. Nat Neurosci 1:487-493.

Takahashi T, Fournier A, Nakamura F, Wang LH, Murakami Y, Kalb RG, Fujisawa H, Strittmatter SM (1999) Plexin-neuropilin-1 complexes form functional semaphorin-3A receptors. Cell 99:59-69.

Tansey MG, Baloh RH, Milbrandt J, Johnson Jr EM (2000) GFRalphamediated localization of RET to lipid rafts is required for effective downstream signaling, differentiation, and neuronal survival. Neuron 25:611-623.

Zinn K, Sun Q (1999) Slit branches out: a secreted protein mediates both attractive and repulsive axon guidance. Cell 97:1-4. 